\title{
Assessment of blood pressure control in adult hypertensive patients in eastern Sudan
}

\author{
Saeed M. Omar ${ }^{1}$, Osama Elnour ${ }^{2}$, Gamal K. Adam, Osman E. Osman ${ }^{3}$ and Ishag Adam ${ }^{4}$ (D)
}

\begin{abstract}
Background: The rate of blood pressure (BP) control in adult hypertensive patients is poor and the reasons for poor control of BP pressure are not fully understood globally. This study aimed to assess the rate and factors associated with BP control in adult hypertensive patients in Sudan.

Methods: A hospital-based cross-sectional study was conducted in adult hypertensive Sudanese patients at Gadarif Hospital in eastern Sudan from November 2016 to March 2017. Information on sociodemographic characteristics of the participants, comorbidities, antihypertensive medication, and adherence to antihypertensive medication was gathered from patients using a questionnaire. Fasting cholesterol and triglyceride levels were measured.

Results: A total of 380 patients were enrolled. Of them, 234 (61.6\%) were women. The mean (SD) age of the participants was 57.8 (11.1) years (range: $25-93$ years). Over one-third ( $n=147,38.7 \%)$ of the participants were taking more than one antihypertensive medication. Approximately one-third (29.5\%) of the participants were nonadherent to medication. The rate of BP control was $45.3 \%$. In binary logistic regression analyses, age, sex, physical inactivity, adding salt to food, drinking coffee, body mass index, and the lipid profile were not associated with uncontrolled BP. However, non-adherence to medication was the main factor associated with uncontrolled BP (odds ratio $=5.29,95 \%$ confidence interval $=3.16-8.83, P<0.001$ ).
\end{abstract}

Conclusions: Almost half of hypertensive patients in follow-up have uncontrolled BP, mainly due to non-adherence to medicine. We recommend further research on drug adherence to improve the rate of BP control in this setting (Gadarif) of the Sudan.

Keywords: Hypertension, Controlled blood pressure, Dyslipidemia, Adherence, Sudan

\section{Background}

Hypertension is estimated to increase from approximately 1.0 billion in 2000 to 1.5 billion by 2025 [1]. Unfortunately, the majority of patients' blood pressure (BP) is poorly controlled in all settings, especially in countries with minimal resources. Uncontrolled BP is defined as BP measurement of $\geq 140 / 90 \mathrm{mmHg}$. Uncontrolled BP is a major health problem and can lead to high morbidity and mortality risks, such as heart failure, coronary heart disease, stroke, and renal insufficiency [2, 3]. Recent publications have reported various rates and determinants for uncontrolled hypertension (e.g., age, sex, education) [4-8].

\footnotetext{
* Correspondence: ishagadam@hotmail.com

${ }^{4}$ Faculty of Medicine, University of Khartoum, P.O. Box 102, Khartoum, Sudan Full list of author information is available at the end of the article
}

Among the known predictors of uncontrolled BP is non-adherence to antihypertensive medications and this can potentiate development of hypertensive complications [3, 9]. Adherence to antihypertensives is defined if the patients take at least $80 \%$ of their medications on a daily basis [10]. Despite the availability of effective medications, control of high BP is well below the expected level. Many factors have been reported to affect the level of adherence to antihypertensives. These factors include the level of education, access to medications, and the number of antihypertensive drugs used by the patients and their adverse effects $[10,11]$.

Hypertension is large health problem in Sudan where $35.7 \%$ of adults in North Sudan are hypertensive [12]. However, there are few published data on hypertension 
in Sudan $[13,14]$. Research on hypertension is important for researchers, clinicians, and health planners. The current study was conducted to examine the rate and associated factors of uncontrolled BP at Gadarif Hospital in eastern Sudan.

\section{Methods}

A cross-sectional study was conducted at Gadarif hospital from November 2016 to March 2017. After explaining the purpose of the study and signing informed consent, adult ( $\geq 20$ years) hypertensive Sudanese patients who visited for follow-up were enrolled. Pregnant women and patients with poor cognitive functions were excluded. Sociodemographic characteristics e.g. age, sex, residence, education, health insurance, marital status, smoking (smokers were subject who smoked more than 100 cigarettes in their lives and reported any past-year smoking), alcohol consumption (one or more drink in the past month), duration of hypertension, and comorbidities (diabetes, thyroid, hyperlipidemia, and stroke) were gathered through a questionnaire which we developed it for this study (Additional file 1).

The participants were classified as physically active if they were being regularly involved in moderate or strenuous leisure activity for $4 \mathrm{~h}$ or more per week; otherwise, they were classified as physically inactive. BP (on the index day of the visit) was measured twice after resting for at least 10 min using an OMRON 3 (with an appropriate-size cuff) automated blood measuring device. The mean of two (at an interval of 1-2 min) blood pressure readings was calculated. The mean of the two readings was recorded. If the difference between the two readings was $>5 \mathrm{mmHg}$, re -measurements were taken until the stability of the reading was reached. The patient's arm was kept/maintained at the level of the heart. Drug adherence was assessed by the Morisky score [15].

The patients' weight and height were measured using standard procedures and body mass index (BMI) was computed as weight/height $\left(\mathrm{m}^{2}\right)$. Cholesterol and triglyceride levels were measured using enzymatic methods.

The sample size of 380 subjects was determined. This sample size was based on previous studies where $40 \%$ of patients had uncontrolled BP [5] to detect a difference of $5 \%$ at $\alpha=0.05$ with a power of $80 \%$. We assumed that $10 \%$ of the participants might not respond or have incomplete data.

A pilot study enrolling 20 participants was conducted, and changes were made in the questionnaires accordingly. The medical officers who collected the data were trained in data collection methods to standardize the data collection procedure to maintain data quality.

\section{Definitions}

Hypertension was defined as sustained high blood pressure (systolic BP $\geq 140$ or diastolic BP $\geq 90 \mathrm{mmHg}$ ) or reported regular use of antihypertensive medication [16]. Uncontrolled BP was defined as systolic BP of $\geq 140 \mathrm{mmHg}$ and/or diastolic BP of $\geq 90 \mathrm{mmHg}$ [17]. Controlled blood pressure was defined as systolic BP of $<140 \mathrm{mmHg}$ and/or diastolic BP of $<90 \mathrm{mmHg}$. Morisky's medication adherence scale (MMAS-8) was used to assess the adherence of antihypertensive among participants who were on treatment. MMAS-8 Scale contained four questions relating to use or forget to take the antihypertensive/medicine (two questions) and self-adjustment of medicine dosages (two questions). The questions have the options "Yes," "No" to reply. The "Yes" and "No" rated answers were assigned a value of 1 , and 0 , respectively. Then, the aggregate number was used and categorized as 0 (high adherence), 1 to 2 (medium adherence), and nonadherence was considered if the score was $\geq 3$ [15].

\section{Statistical analysis}

Data were entered into a computer using SPSS for Windows (version 20.0). The chi-square test was used to compare proportions between patients with controlled and uncontrolled BP. The Kolmogorov-Smirnov test was used for testing the normality of continuous data (age, duration of hypertension, BMI, and lipid profile). The Student's t-test and Mann-Whitney test were used to compare continuous parametric and non-parametric data, respectively, between the two groups (controlled and uncontrolled $\mathrm{BP}$ ). Binary regression analyses were performed with uncontrolled $\mathrm{BP}$ as the dependent variable. Independent variables (age, sex, marital status, education, presence of comorbidity, alcohol intake, coffee intake, physical activity, measuring blood pressure at home, having medical insurance, BMI, and the lipid profile) were entered into the model if their univariate $\mathrm{P}$ was $<0.20$. Odds ratios (ORs) and $95 \%$ confidence intervals (CIs) were calculated and a $P$ value of $<0.05$ was considered significant.

\section{Results}

A total of 380 adult hypertensive patients were enrolled in the study. Among them, 234 (61.6\%) patients were women. The mean (SD) age of the participants was 57.8 (11.1) years (range: $25-93$ years). The majority (82.6) of the participants were married. Approximately two-fifths (44.7\%) of the participants ingested salt with food. Fortytwo (11.1\%) participants were cigarette smokers and 12 (3.2\%) were alcohol drinkers. The majority $(58.2 \%)$ of the participants were drinking coffee. A total of 270 (71.8) participants had medical insurance (Table 1). The mean (SD) duration of hypertension was 6.7 (5.8) years. Half of the patients (50.3\%) had hypertension for $\geq 5$ years. 
Table 1 The clinical and biochemical characteristics in adult hypertensive patient, eastern Sudan

\begin{tabular}{|c|c|c|}
\hline Variable & Value & Percentage \\
\hline Age (years) ${ }^{a}$ & 57.8 & 11.1 \\
\hline Male sex & 146 & 38.4 \\
\hline Education $\leq$ secondary level & 361 & 95.0 \\
\hline Married & 314 & 82.6 \\
\hline Duration of hypertension, years ${ }^{\dagger}$ & 5.0 & $53.0-8.0$ \\
\hline Presence of comorbidity & 184 & 48.4 \\
\hline Smoking/ex-smoking & 42 & 11.1 \\
\hline Alcohol intake & 12 & 3.2 \\
\hline Drinking coffee & 220 & 58.0 \\
\hline Physically active & 16 & 4.2 \\
\hline Adherence to drugs & 268 & 70.5 \\
\hline Measuring blood pressure at home & 22 & 5.8 \\
\hline Have medical insurance & 273 & 71.8 \\
\hline Taking traditional medicine & 24 & $24(6.3)$ \\
\hline Body mass index, $\mathrm{kg} / \mathrm{m}^{2 \mathrm{~b}}$ & 26.2 & $23.4-28.4$ \\
\hline Cholesterol, mg/dl ${ }^{\mathrm{b}}$ & 179.7 & $156.0-210.0$ \\
\hline Triglycerides, mg/dl ${ }^{b}$ & 146.0 & $115.0-190.0$ \\
\hline
\end{tabular}

Over one-third ( $n=147,38.7 \%)$ of the participants were taking more than one antihypertensive medication. Approximately two-thirds $(n=259,68.2 \%)$ of the participants were using calcium channel blockers (amlodipine). A total of 132 (34.7\%), 59 (15.5\%), 45 (11.8\%), and 24 (6.3\%) of the participants were using angiotensin II receptor blockers (lisinopril), angiotensin-converting enzyme inhibitors (losartan), beta-blockers (atenolol), and diuretics (hydrochlorothiazide), respectively (Fig. 1). The most common comorbidities were diabetes $(n=124$, $32.6 \%)$, thyroid disease $(n=19,5.0 \%)$, previous ischemic disease $(n=17,4.5 \%)$, previous stroke $(n=15,3.9 \%)$, heart failure $(n=4,1.1 \%)$, and renal disease $(n=5,1.3 \%)$. The mean (SD) systolic and diastolic blood pressure was 134.3 (15.8) $\mathrm{mm} \mathrm{Hg}$ and 89.3 (46.3) $\mathrm{mm} \mathrm{Hg}$, respectively.

Approximately one-third (29.5\%) of the participants were non-adherent to medication. The rate of BP control was $45.3 \%$. There were no significant differences in age, sex, education, duration of hypertension, presence of comorbidity, drinking coffee, and alcohol intake between participants with controlled BP and those with uncontrolled BP. A significantly higher number of participants with uncontrolled BP were non-adherent to medicine and had higher cholesterol and triglyceride levels compared with those with controlled BP (all $P<0.001$, Table 2).

In binary logistic regression analyses, age, sex physical inactivity, adding salt to food, drinking coffee, BMI, and the lipid profile were not associated with uncontrolled BP. However, non-adherence to medication was associated with uncontrolled $\mathrm{BP}(\mathrm{OR}=5.29,95 \% \mathrm{CI}=$ 3.16-8.83, $P<0.001$, Table 3).

\section{Discussion}

The main findings of the current study were that the rate of uncontrolled BP was $45.3 \%$ and non-adherence to medication was the only factor associated with uncontrolled BP. In neighboring Ethiopia, Asgedom et al. reported that the rate of $\mathrm{BP}$ control was $50.3 \%$ and more than one-third $(39.5 \%)$ of the participants were nonadherent to their medication [6]. Generally, our finding of the rate of BP control (54.7\%) is similar to that in other African countries. The rate of BP control is $46.6 \%$, $47.7 \%$, and $41.9 \%$ in Ethiopia, Tanzania, and South Africa, respectively [18-20]. However, much lower BP control (24.6\%) was reported in Cameroon [21]. The reason for this lower rate of BP control in Cameroon could be because a population-based study was performed, while facility-based findings were reported in other studies.

In the current study, there was no association between sociodemographic characteristics (including age, sex, and alcohol) and uncontrolled BP. These findings are similar to those observed in Tanzania, Cameron, and Nepal $[7,8,19]$. These findings are in contrast to those in a study conducted in Ethiopia in which age, physical inactivity, chat chewing, adding salt to food, and drinking coffee were significantly associated with uncontrolled BP [6]. In our study, education and health insurance status were not significantly associated with BP control. These findings are similar to those reported in Tanzania and Cameroon $[8,19]$. However, in the United States, a previous study showed that among patients who were treated for hypertension, uninsured individuals were at higher risk of uncontrolled BP [22]. Notably, the rate (71.8\%) of medical insurance in this setting of eastern Sudan was lower than that (87.5\%) of medical insurance that was recently observed in Cameroon [8].

Our study showed a significant association of uncontrolled BP with non-adherence to antihypertensive medication, where non-adherent participants had a 5.29 times higher risk of uncontrolled BP. This finding is consistent with previous studies in various settings $[6,8,19]$. Our finding that $29.5 \%$ of the participants were non-adherent to medication is lower than previously observed in Kassala in eastern Sudan [14]. This previous study showed that $59.6 \%$ of patients were compliant to their medication as assessed by a different method (pill count method). Recently, Asgedom et al. reported that $39.5 \%$ of hypertensive Ethiopian patients were not adherent to medicine [6]. Low adherence to antihypertensive treatment is associated with a significant increase in the risk of cardiovascular events and a higher rate of hospital admission [23, 24]. Therefore, adherence to antihypertensive medicine in this setting should be encouraged. Previous studies have shown that 


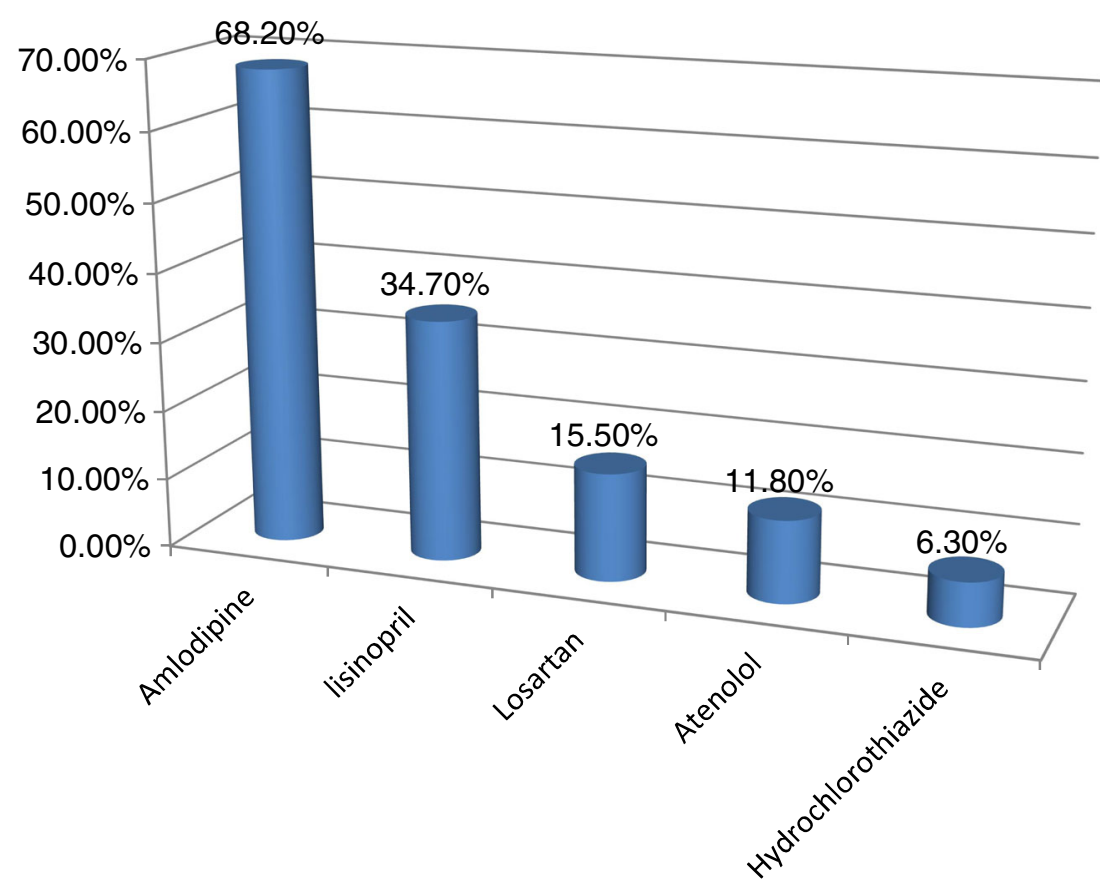

Fig. 1 Antihypertensive drugs used by the patients in eastern Sudan

participants were not adherence and intentionally avoided antihypertensive because of; long term medication and fearing side effects [7], complexity of the regimen used in the the treatment of asymptomatic disease (hypertension) [25].Various aspects of the new guidelines aimed to assist researchers working on hypertension in the term of; lifestyle; nutrition, new drugs and adopting effective drug delivery systems have been recently reviewed and these might improve to control hypertension and reducing its complications [26].

Table 2 Comparison of clinical and biochemical characteristics between patients with controlled and uncontrolled blood pressure

\begin{tabular}{|c|c|c|c|c|c|}
\hline Variable & $\begin{array}{l}\text { Controlled blood } \\
\text { pressure }(n=208)\end{array}$ & $\begin{array}{l}\text { Uncontrolled blood } \\
\text { pressure }(n=172)\end{array}$ & OR & $95 \% \mathrm{Cl}$ & $P$ \\
\hline Age, years & $58.1(10.9)$ & $57.4(11.4)$ & 0.94 & $0.97-1.01$ & 0.533 \\
\hline Male sex & $74(35.6)$ & $72(41.9)$ & 0.76 & $0.50-1.16$ & 0.244 \\
\hline Education $\leq$ secondary level & $202(97.1)$ & $159(92.4)$ & 0.36 & $0.13-0.97$ & 0.056 \\
\hline Married & $169(81.2)$ & $145(84.3)$ & 0.90 & $0.60-1.36$ & 0.647 \\
\hline Duration of hypertension, years & $5.5(2.0-8.0)$ & $5.0(3.0-8.0)$ & 1.01 & $0.97-1.04$ & 0.523 \\
\hline Presence of comorbidity & $103(49.5)$ & $81(47.1)$ & 0.90 & $0.60-1.36$ & 0.680 \\
\hline Smoking/ex-smoking & $17(8.2)$ & $25(14.5)$ & 1.91 & $0.99-3.67$ & 0.070 \\
\hline Alcohol intake & $4(1.9)$ & $8(4.7)$ & 2.48 & $0.73-8.40$ & 0.150 \\
\hline Drinking coffee & $119(57.2)$ & $101(59.1)$ & 1.07 & $0.71-1.62$ & 0.754 \\
\hline Physically active & $8(3.8)$ & $8(4.7)$ & 1.22 & $0.44-3.32$ & 0.799 \\
\hline Adherence to drugs & $179(86.1)$ & $89(51.7)$ & 0.17 & $0.10-0.28$ & $<0.001$ \\
\hline Measuring blood pressure at home & $13(6.2)$ & $9(5.2)$ & 0.82 & $0.34-1.98$ & 0.826 \\
\hline Have medical insurance & $150(72.1)$ & $123(71.8)$ & 0.97 & $0.62-1.52$ & 0.909 \\
\hline Taking traditional medicine & $13(6.3)$ & $11(6.4)$ & 1.02 & $0.44-2.34$ & 1.000 \\
\hline Body mass index, $\mathrm{kg} / \mathrm{m}^{2}$ & $26.2(23.1-28.0)$ & $26.2(23.7-29.0)$ & 1.02 & $0.98-1.06$ & 0.282 \\
\hline Cholesterol, mg/dl & $168.0(142.2-194.2)$ & $190.0(160.0-210.0)$ & 1.01 & $1.01-1.03$ & 0.001 \\
\hline Triglycerides, mg/dl & $130.0(111.2-167.0)$ & $158.4(124.2-195.0)$ & 1.01 & $10.1-1.07$ & 0.001 \\
\hline
\end{tabular}

Values are mean (SD) or median (interquartile range) 
Table 3 Binary regression analyses of factors related to uncontrolled blood pressure in eastern Sudan

\begin{tabular}{llll}
\hline Variable & OR & $95 \% \mathrm{Cl}$ & $P$ \\
\hline Male sex & 0.87 & $0.53-1.43$ & 0.594 \\
Education $\leq$ secondary level & 0.38 & $0.12-1.16$ & 0.091 \\
Smoking/ex-smoking & 1.79 & $0.85-3.79$ & 0.123 \\
Alcohol intake & 1.03 & $0.28-3.83$ & 0.955 \\
Non-adherence to drugs & 5.29 & $3.16-8.83$ & $<0.001$ \\
Cholesterol, mg/dl & 1.01 & $0.99-1.01$ & 0.161 \\
Triglycerides, mg/dl & 1.01 & $0.99-1.01$ & 0.750 \\
\hline
\end{tabular}

\section{Limitations}

There are some limitations of this study. One of the limitations of the current study was that it was a facilitybased study. The actual rate of uncontrolled BP might have been underestimated in this study because it might not have reflected BP at the community level.

\section{Conclusions}

Almost half of the hypertensive patients at follow-up in a hospital in eastern Sudan have uncontrolled BP, mainly due to non-adherence to medicine. We recommend better health education and research on drug adherence to improve the rate of $\mathrm{BP}$ control in this setting.

\section{Additional file}

Additional file 1: Questionnaire for the assessment of blood pressure control in adult hypertensive patients in eastern Sudan. (PDF $338 \mathrm{~kb}$ )

\section{Abbreviations}

BMl: Body mass index; BP: Blood pressure; Cl: Confidence interval; ORs: Odds ratios; SD: Standard deviation

\section{Acknowledgments}

We thank Ellen Knapp, PhD, from Edanz Group (www.edanzediting.com/ac) for editing a draft of this manuscript.

\section{Funding}

None received.

\section{Availability of data and materials}

The datasets used and/or analyzed during the current study are available from the corresponding author on reasonable request.

\section{Ethics approval and consent to participate}

The study received ethical approval from the Research Board at the Faculty of Medicine, University of Gadarif, Sudan. The reference number is 2016/18. Written informed consent was obtained from all the enrolled patients.

\section{Authors' contributions}

$\mathrm{SMO}, \mathrm{OE}$, and IA conceived and designed the study. OE, GKA, and OEO recruited the participants. SMO, OEO, GKA and IA analyzed the data and wrote the manuscript. All contributive authors of this original manuscript authorized the final version of the manuscript. All authors read and approved the final manuscript.

\section{Consent for publication}

Not applicable.

\section{Competing interests}

The authors declare that they have no competing interests.

\section{Publisher's Note}

Springer Nature remains neutral with regard to jurisdictional claims in published maps and institutional affiliations.

\section{Author details}

${ }^{1}$ Faculty of Medicine, Gadarif University, Gadarif, Sudan. ${ }^{2}$ Faculty of Medicine, Omdurman University, Omdurman, Sudan. ${ }^{3}$ Faculty of Medicine, Alneelain University, Khartoum, Sudan. ${ }^{4}$ Faculty of Medicine, University of Khartoum, P.O. Box 102, Khartoum, Sudan.

Received: 25 October 2017 Accepted: 2 February 2018

Published online: 07 February 2018

\section{References}

1. Mufunda J, Mebrahtu G, Usman A, Nyarango P, Kosia A, Ghebrat Y, et al. The prevalence of hypertension and its relationship with obesity: results from a national blood pressure survey in Eritrea. J Hum Hypertens. 2006;20:59-65.

2. Chobanian AV, Bakris GL, Black HR, Cushman WC, Green LA, Izzo JL, et al. Seventh report of the joint National Committee on prevention, detection, evaluation, and treatment of high blood pressure. Hypertension. 2003:42:1206-52.

3. Handler J, Lackland DT. Translation of hypertension treatment guidelines into practice: a review of implementation. J Am Soc Hypertens. 2011:5:197-207.

4. Al Ghobain M, Alhashemi H, Aljama A, Bin Salih S, Assiri Z, Alsomali A, et al. Nonadherence to antihypertensive medications and associated factors in general medicine clinics. Patient Prefer Adherence. 2016;10:1415-9.

5. Al-Baghli NA, Al-Turki KA, Al-Ghamdi AJ, El-Zubaier AG, Al-Baghli FA Bohlaiqa NH. Control of hypertension in eastern Saudi Arabia: results of screening campaign. J Family Community Med. 2009;16:19-25.

6. Asgedom SW, Gudina EK, Desse TA. Assessment of blood pressure control among hypertensive patients in Southwest Ethiopia. PLoS One. 2016:11:e0166432

7. Devkota S, Dhungana RR, Pandey AR, Bista B, Panthi S, Thakur KK, et al. Barriers to treatment and control of hypertension among hypertensive participants: a community-based cross-sectional mixed method study in municipalities of Kathmandu, Nepal. Front Cardiovasc Med. 2016;3:26.

8. Menanga A, Edie S, Nkoke C, Boombhi J, Musa AJ, Mfeukeu LK, et al. Factors associated with blood pressure control amongst adults with hypertension in Yaounde, Cameroon: a cross-sectional study. Cardiovasc Diagn Ther. 2016;6:439-45.

9. Munger MA, Van Tassell BW, La Fleur J. Medication nonadherence: an unrecognized cardiovascular risk factor. MedGenMed. 2007;9:58.

10. Nair KV, Belletti DA, Doyle JJ, Allen RR, McQueen RB, Saseen JJ, et al. Understanding barriers to medication adherence in the hypertensive population by evaluating responses to a telephone survey. Patient Prefer Adherence. 2011;5:195-206.

11. Oliveira-Filho AD, Barreto-Filho JA, SJF N, De LJDP. Association between the 8-item Morisky medication adherence scale (MMAS-8) and blood pressure control. Arq Bras Cardiol. 2012;99:649-58.

12. Bushara S, Noor S, Ibraheem AA, Elmadhoun W, Ahmed M. Prevalence of and risk factors for hypertension among urban communities of North Sudan: detecting a silent killer. J fam med Prim Care. 2016:5:605-10.

13. Babiker FA, Elkhalifa LA, Moukhyer ME. Awareness of hypertension and factors associated with uncontrolled hypertension in Sudanese adults. Cardiovasc J Afr. 2013;24:208-12.

14. Elzubier AG, Husain AA, Suleiman IA, Hamid ZA. Drug compliance among hypertensive patients in Kassala, eastern Sudan. East Mediterr Health J. 2000;6:100-5.

15. Morisky DE, Green LW, Levine DM. Concurrent and predictive validity of a self-reported measure of medication adherence. Med Care. 1986;24:67-74

16. van de Vijver S, Akinyi H, Oti S, Olajide A, Agyemang C, Aboderin I, et al. Status report on hypertension in Africa-consultative review for the 6th session of the African union conference of ministers of health on NCD's. Pan Afr Med J. 2013;16:38.

17. Muxfeldt ES, Nogueira Ada R, Salles GF, Bloch KV. Demographic and clinical characteristics of hypertensive patients in the internal medicine outpatient clinic of a university hospital in Rio de Janeiro. Sao Paulo Med J. 2004;122:87-93. 
18. Ambaw AD, Alemie GA, SM W/Y, Mengesha ZB. Adherence to antihypertensive treatment and associated factors among patients on follow up at University of Gondar Hospital, Northwest Ethiopia. BMC Public Health. 2012;12:282.

19. Maginga J, Guerrero M, Koh E, Holm Hansen C, Shedafa R, Kalokola F, et al. Hypertension control and its correlates among adults attending a hypertension clinic in Tanzania. J Clin Hypertens (Greenwich). 2016;18:207-16.

20. Adebolu FA, Naidoo M. Blood Pressure control amongst patients living with hypertension presenting to an urban district hospital outpatient clinic in Kwazulu-Natal. African J Prim Heal Care Fam Med 2014; 6(1):E1-E6.

21. Dzudie A, Kengne AP, Muna WFT, Ba H, Menanga A, Kouam Kouam C, et al. Prevalence, awareness, treatment and control of hypertension in a selfselected sub-Saharan African urban population: a cross-sectional study. BMJ Open 2012;2 2(4). pii: e001217.

22. Duru OK, Vargas RB, Kermah D, Pan D, Norris KC. Health insurance status and hypertension monitoring and control in the United States. Am J Hypertens. 2007;20:348-53.

23. Yang Z, Howard DH, Will J, Loustalot F, Ritchey M, Roy K. Association of antihypertensive medication adherence with healthcare use and medicaid expenditures for acute cardiovascular events. Med Care. 2016;54:504-11.

24. Khalil S, Almobarak AO, Awadalla H, Elmadhoun WM, Noor SK, Sulaiman AA, et al. Low levels of physical activity in Sudanese individuals with some features of metabolic syndrome: population based study. Diabetes Metab Syndr Clin Res Rev. 2017; [Epub ahead of print]

25. George J, Phun YT, Bailey MJ, Kong DC, Stewart K. Development and validation of the medication regimen complexity index. Ann Pharmacother. 2004;38(9):1369-76.

26. Okur ME, Karantas ID, Okur NÜ, Siafaka PI Hypertension in 2017: Update in treatment and pharmaceutical innovations. Curr Pharm Des 2017 Sep 27. https://doi.org/10.2174/1381612823666170927123454. [Epub ahead of print].

\section{Submit your next manuscript to BioMed Central and we will help you at every step:}

- We accept pre-submission inquiries

- Our selector tool helps you to find the most relevant journal

- We provide round the clock customer support

- Convenient online submission

- Thorough peer review

- Inclusion in PubMed and all major indexing services

- Maximum visibility for your research

Submit your manuscript at www.biomedcentral.com/submit

) Biomed Central 